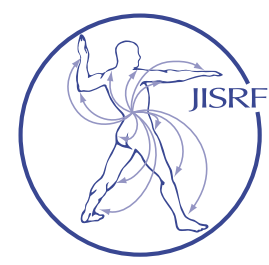

\title{
Restoration of Femoral Condylar Anatomy for Achieving Optimum Functional Expectations: Continuation of an Earlier Study At 5-Year Minimum Follow-Up
}

Durbhakula $S^{1}$, Durbhakula $V^{1}$, Durbhakula $N^{1}$

\section{Abstract}

Background: Studying and reporting the continuous, prospective outcomes of a post-surgical orthopaedic population without loss to follow-up at various standard landmarks over time is rarely achieved in total knee arthroplasty (TKA) literature. Small case series populations reported at an early follow-up time is common, and usually not beyond any initial publication for further reporting. The purpose of this study was to advance the knowledge base of the performance of Freedom Knee system through the continuous monitoring of a previously reported early series TKA patient population.

Methods: A prospective, continuous series of 176 primary posterior stabilized (PS) TKAs were performed in 172 patients by a single surgeon. Femoral component size distribution was assessed and all patients were followed for a minimum of five-years post-operatively. Total Hospital for Special Surgery (HSS) scores and range of motion (ROM) was assessed for the entire cohort and by gender.

Results: There were no patients lost to follow-up. Two patients required early post-operative incision and drainage for superficial wound infection of the indicated knees. One patient required tibial component and polyethylene insert revision following a motor vehicle accident resulting in a proximal tibial fracture and component loosening. There was no radiographic evidence of component failure. As expected, femoral component size frequency use was skewed by gender with the larger sizes in males. There were no pre- or post-operative clinical or functional differences by gender and at the recent follow-up (avg. 6.9 years). In addition, there was an average significant increase in change of HSS score $(\mathrm{p}<0.001)$ and ROM $(\mathrm{P}<0.001)$ when compared to pre-operative baseline but no significant difference in HSS or ROM between the two and five-year outcome results.

Conclusions: The design characteristic for component sizing and functional expectations were re-confirmed in the reported Western population cohort series, and observed optimum safety, performance and efficacy through five-years. Further continued study efforts of this primary TKA system is warranted across multiple surgeons and all ethnic cultures.

\section{Background}

Studying and reporting the continuous, prospective outcomes of a post-surgical orthopaedic population without loss to follow-up at various standard landmarks over time is rarely achieved in total knee arthroplasty (TKA) literature. $[1,2]$ Small case series populations reported at an

Keywords: total knee; condylar anatomy

Level of Evidence: AAOS Therapeutic Level III 
early follow-up time is common, and usually not beyond any initial publication for further reporting. [3,] Equally common is reporting the "average time to follow-up" across a large range of time post-operatively. [4, 5$]$ There exists a number of well known reasons for discontinuing review of an initial population including lack of interest due to removal of the original component offering, changes in component design, new competitive product offerings, change in surgeon / corporate alliance, and surgical practice growth reducing the ability to track all patients.

Of the few long-term continuous reports, the publication series on the cemented Total Condylar prosthesis (Johnson \& Johnson, New Brunswick, NJ; Howmedica, Rutherford, NJ) spans 20 years, $[1, \underline{1}, \underline{6}-\underline{]}]$ and the Press-Fit Condylar (DePuy Orthopaedics, Warsaw, IN) has been reported through 25 years. [9] The authors have followed the long-term results of their respective original populations through various post-operative landmarks that yielded multiple intermediate publications. [10-14] In all, these study series have revealed successful "performance and reliability of a surgical procedure", the long-term durability of the prosthetic composite and has set benchmarks by which other component series are studied and understanding on the longevity and outcome of these devices and patient population.

The design concept and early results of 176 MAXX Freedom Total Knee ${ }^{\circledR}$ system TKA patients, with a minimum follow-up at 2-years, have been previously published. [15] In an effort to advance the knowledge of the prospective results of the Freedom TKA system, the original patient population identified in the previously published study was monitored through their 5-year followup landmark. The purpose of this study was to advance the knowledge base of the performance of Freedom Knee system through the continuous monitoring of a previously reported early series TKA patient population.

\section{Materials and Methods}

As was previous reported at the two-year post-operative follow-up, between November 2010 and December 2013, the senior author performed 176 consecutive primary TKAs in 172 patients, without selection, utilizing the posterior stabilized (PS) Freedom Total Knee ${ }^{\circledR}$ system (MAXX Orthopedics, Inc., Norristown, Pennsylvania) (Figure 1). [15] The Freedom Total Knee system is manufactured from cast cobalt chromium (ASTM F-75 CoCrMo), and the articular bearing surfaces use ram-extruded UHMWPE (GUR 1020). The Freedom Total Knee system was also designed with the intent to address bone conser-
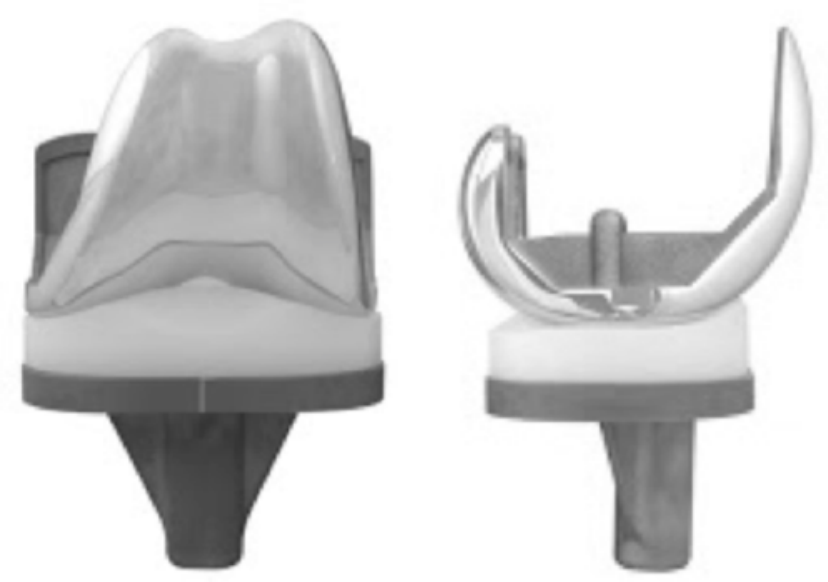

Figure 1. Anterior-Postetior and Lateral views of the Posterior Stabilized (PS) Freedom Total Knee ${ }^{\circledR}$ system (MAXX Orthopedics, Inc., Norristown, Pennsylvania).

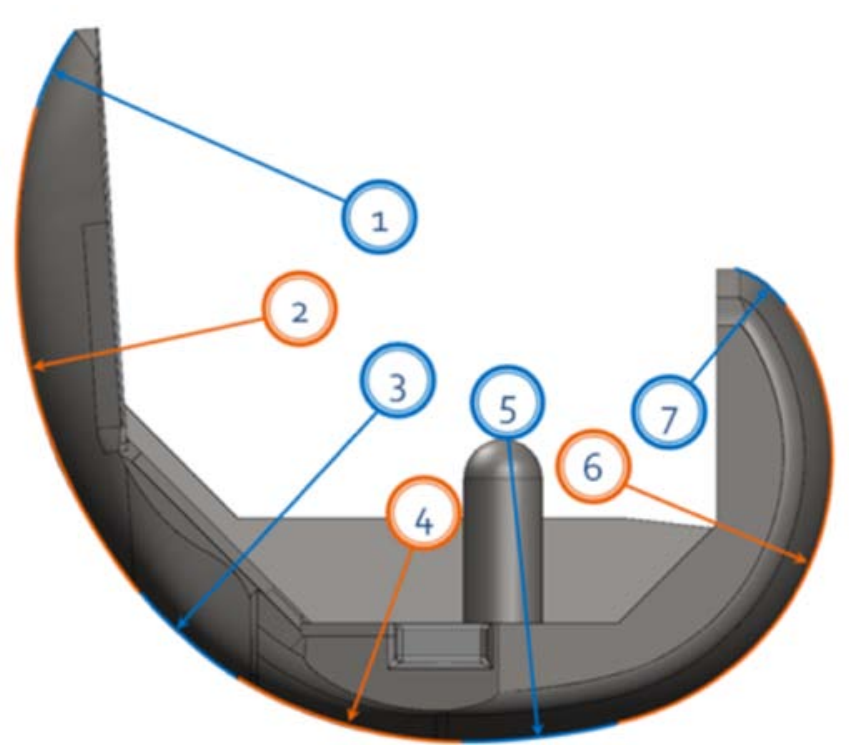

Figure 2. Multi-radius design of the Freedom Knee in which seven tangential radii were incorporated to accommodate changes in rollback across the available surface through the transition from walking through deep flexion. Radii 1, 2 and 3 manage patellofemoral contact, and radii 4, 5, 6 and 7 control femoral rollback and flexion.

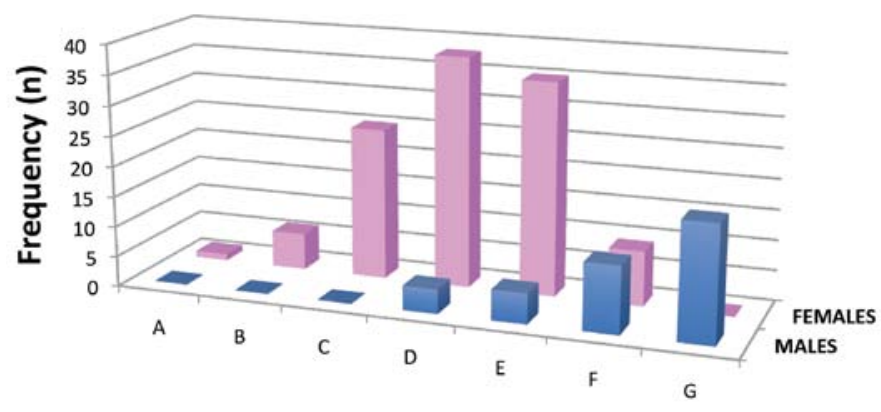

Femoral Component Size

Figure 3. Distribution of component size by gender. 
vation while permitting optimal high-flexion motion up to 155 degrees, dependent on the patient's anatomy and cultural activities of daily living, such as frequent and prolonged squatting and kneeling. To achieve high-flexion, the femoral component was engineered utilizing a multiradius design in which seven tangential radii were incorporated to accommodate changes in rollback across the available surface through the transition from walking through deep flexion (Figure 2). In addition, development of femoral component sizing was optimized to include the anthropomorphic dimensions of Western and Pan-Asian patient populations.

Of the 172 patients studied, there were 129 females (75.0\%) and 43 males (25.0\%) with an average patient age at surgery of $69.7 \pm 7.6$ years (range: 52.3 years to 98.6 years). The average age of the female patient (69.3 years) when compared to the male patients (70.7 years) was not significantly different $(\mathrm{p}=0.311)$. (Table 1$)$ In this continuous series, four female patients underwent bilateral TKA under the same anesthesia. In this set of patients, the pre-operative diagnosis was predominately degenerative joint disease (DJD) in 170 knees $(96.6 \%)$ and rheumatoid arthritis (RA) in 6 knees (3.4\%). The surgical side was evenly distributed across all patients with 86 left $(48.9 \%)$ and 90 right $(51.1 \%)$ knees (Table 1). In all cases the deep-vein thrombosis (DVT) prophylaxis was Lovenox ${ }^{\circledR}$ (SanofiAventis, Bridgewater, NJ).

\section{Results}

All 172 originally studied patients had a post-operative minimum follow-up of 5-years with an average time to follow-up of $6.5 \pm 0.9$ years (range: 5.0 years to 8.1 years). Overall, the pre-operative Hospital for Special Surgery (HSS) score was $49.2 \pm 5.7$ (range: 40.0 to 65.0 ), which significantly improved to a 2-year follow-up average of 88.4 \pm 3.6 (range: 80.0 to 95.0$)(\mathrm{p}<0.001)$ and remained statistically identical a 5-year follow-up average of $88.8 \pm 3.4$ (range: 80.0 to 95.0$)(\mathrm{p}<0.001$ Table 2$)$. As observed with the HSS at 2-years minimum follow-up, there was no statistical difference in pre-operative $(\mathrm{p}=0.208), 2$-years postoperative $(\mathrm{p}=0.939), 5$-years post-operative $(\mathrm{p}=0.366)$ or any difference between 2 - and 5-years $(\mathrm{p}=0.505)$ by gender for HSS.

Functionally, the pre-operative range of motion (ROM) was $113.8 \pm 6.1$ degrees (range: 95 degrees to 125 degrees), which significantly improved at the 2-year mini-
Table 1. Patient Demographics - there was no statistical difference in patient age at $p=0.311$. Also, there were 172 patients with 176 TKAs (4 bilateral cases).

\begin{tabular}{|l|l|l|l|}
\hline & $\mathbf{n}$ & Males & Females \\
\hline Total Patients & $172(100 \%)$ & $43(25.0 \%)$ & $129(75.0 \%)$ \\
\hline Average Age & $69.7 \pm 7.9$ years & $70.7 \pm 7.3$ years & $69.3 \pm 7.7$ years \\
\hline Side & $\mathrm{R}=86(48.9 \%)$ & $\mathrm{R}=21(51.2 \%)$ & $\mathrm{R}=86(48.1 \%)$ \\
$\mathrm{L}=90(51.1 \%)$ & $\mathrm{L}=22(48.8 \%)$ & $\mathrm{L}=67(48.1 \%)$ \\
\hline $\begin{array}{l}\text { Pre- } \\
\text { Operative } \\
\text { Diagnoses }\end{array}$ & & & \\
\hline DJD & $170(96.6 \%)$ & $43(100.0 \%)$ & $123(95.0 \%)$ \\
\hline RA & $6(3.4 \%)$ & $0(0.0 \%)$ & $6(5.0 \%)$ \\
\hline
\end{tabular}

Table 2. Independent of gender, changes in HSS and ROM from pre- to either postoperative follow-up landmarks were statistically significant $(p<0.001)$. There was pre-operative or post-operative HSS or ROM.

\begin{tabular}{|l|l|l|l|}
\hline & Total Population & Males & Females \\
\hline Avg Follow-Up & $6.5 \pm 0.9$ years & $6.3 \pm 1.1$ years & $6.7 \pm 0.9$ years \\
\hline HSS Score & & & \\
\hline Pre-Operative & $49.2 \pm 5.7$ & $48.3 \pm 5.6$ & $49.5 \pm 5.7$ \\
\hline 2-Years Follow-Up & $88.4 \pm 3.6^{*}$ & $88.4 \pm 4.2^{*}$ & $88.4 \pm 3.4^{*}$ \\
\hline 5-Years Follow-Up & $88.8 \pm 3.4^{*} \#$ & $89.2 \pm 2.9^{* \#}$ & $88.6 \pm 3.5^{* \#}$ \\
\hline Range of Motion & & & \\
\hline Pre-Operative & $113.8 \pm 6.1$ & $114.3 \pm 6.0$ & $113.7 \pm 6.2$ \\
\hline 2-Years Follow-Up & $128.5 \pm 4.1^{*}$ & $128.3 \pm 3.8^{*}$ & $128.5 \pm 4.3^{*}$ \\
\hline 5-Years Follow-Up & $128.7 \pm 4.1^{* \#}$ & $128.6 \pm 3.7^{* \#}$ & $128.7 \pm 4.3^{* \#}$ \\
\hline
\end{tabular}

* Statistically significant difference from baseline at $\mathrm{p}<0.001$

\# No statistical difference between 2-year and 5-year follow-up results

mum follow-up ROM of $128.5 \pm 4.3$ degrees (range: 110 degrees to 140 degrees) to an average 5-year post-operative ROM of $128.7 \pm 4.1$ degrees (range: 115 degrees to 140 degrees). The change in ROM was statistically significant at $\mathrm{p}<0.001$. There was no statistical difference in pre-operative $(\mathrm{p}=0.566)$, two-years $(\mathrm{p}=0.702)$ or five-years $(\mathrm{p}=0.913)$ in ROM by gender. All pre- and post-operative HSS and ROM data is summarized in Table 2. There was no radiographic evidence of aseptic component loosening or osteolysis (Figures 4A-4C).

As was previously reported, two patients $(1.1 \%)$ required subsequent incision and drainage surgery for superficial wound infections. Following these procedures both patients went on to successful clinical and functional outcomes through two and five-years post-operatively. No other patient had any subsequent infection through fiveyears. However, at 4.5-years post-index TKA, one female patient $(<1 \%)$ with a previously well-functioning, Free- 


\section{FIGURES $4 A-C$}
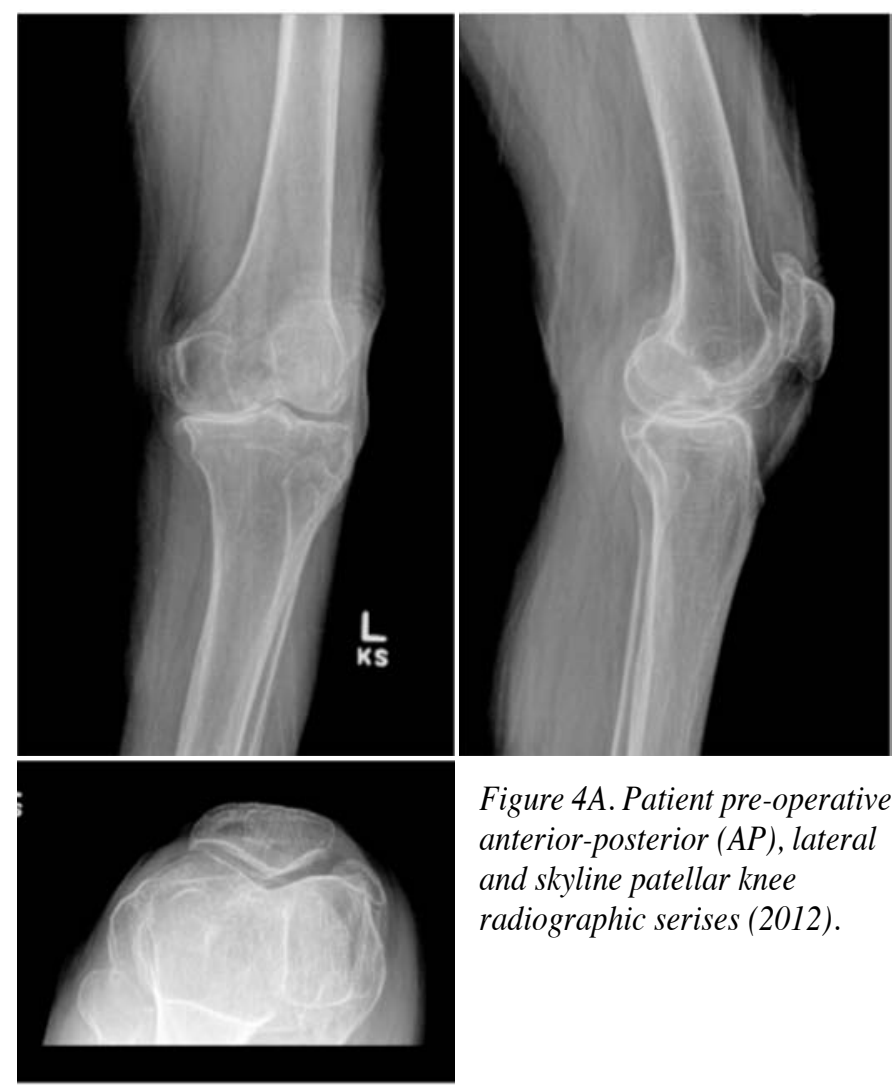

Figure 4A. Patient pre-operative anterior-posterior $(A P)$, lateral and skyline patellar knee radiographic serises (2012).
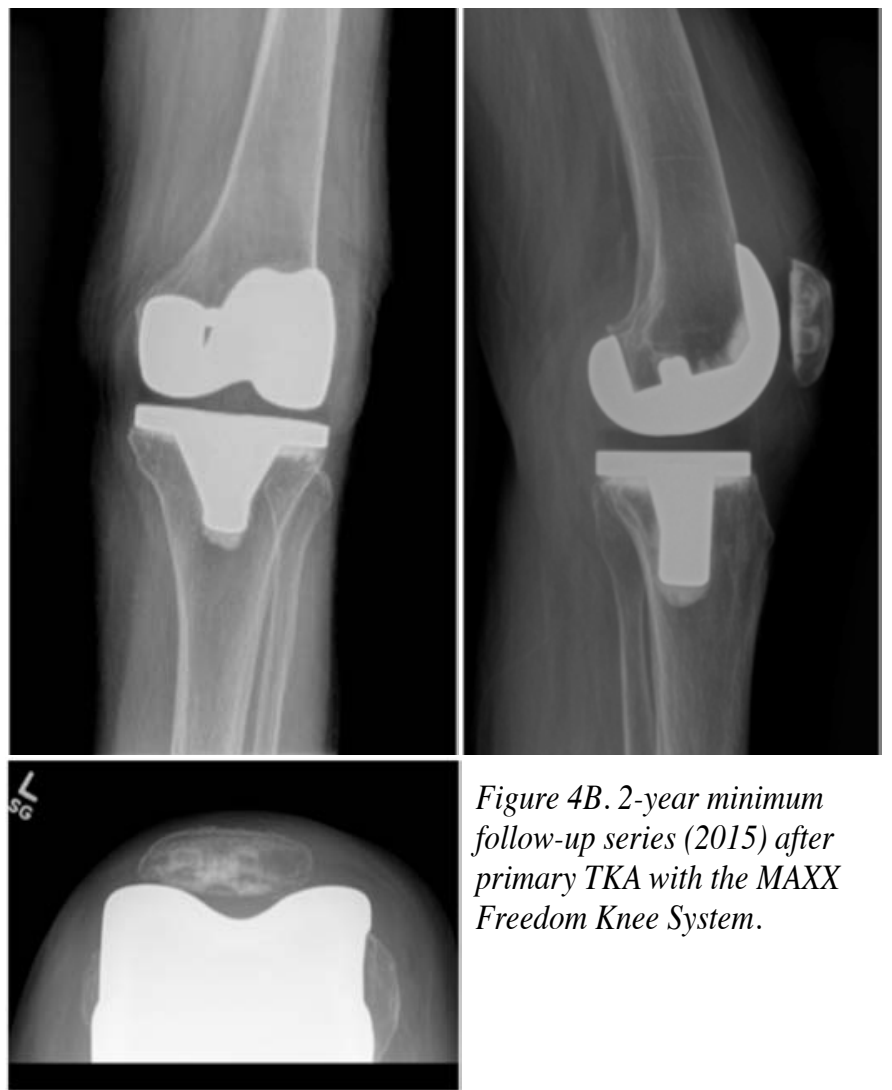

Figure 4B. 2-year minimum follow-up series (2015) after primary TKA with the MAXX Freedom Knee System.
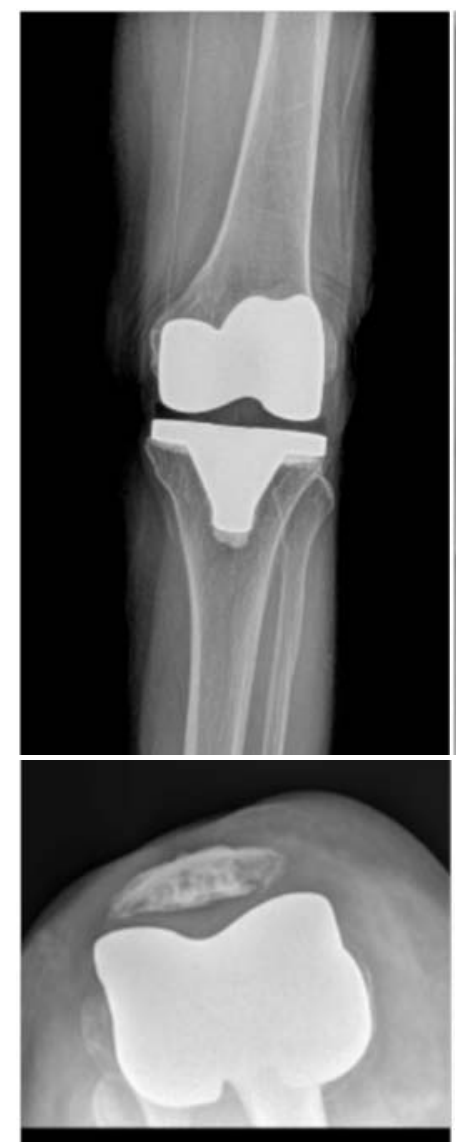

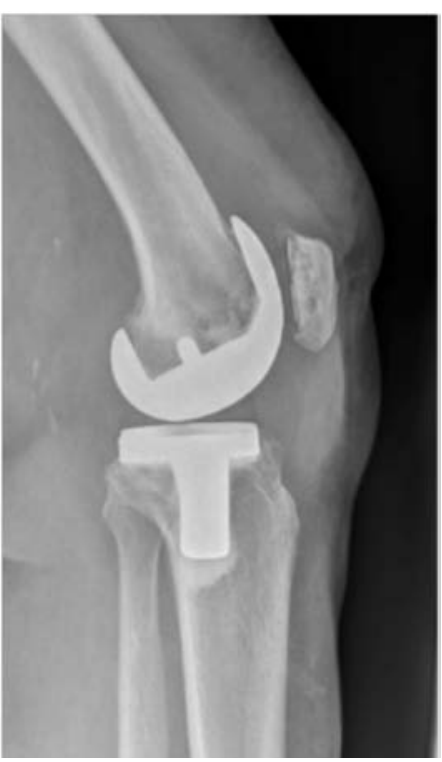

Figure 4C. 5-year minimum AP radiographic follow-up (2018) after primary TKA with the MAXX Freedom Knee System. dom Total Knee system prosthesis was involved in a motor-vehicle accident (MVA) that resulted in chronic pain and decrease of function involving the left proximal tibia. There was radiographic evidence of a proximal tibial stress fracture and tibial component loosening which were confirmed at the time of tibial component revision. Only the index tibial component and polyethylene insert were removed and a cemented MAXX Freedom ${ }^{\circledR}$ Knee Revision tibial baseplate (MAXX Orthopedics, Inc., Plymouth Meeting, Pennsylvania) with an extended tibial stem and PS polyethylene tibial insert were implanted without the use of any other adjunctive fixation hardware. The patient recovered without issue and at the most recent follow-up is well functioning without pain or ambulatory deficit.

\section{Discussion}

We report on the minimum five-year follow-up of a single surgeon, non-randomized, consecutive case series of patients that received the Freedom Total Knee system for primary TKA. This is the second prospective follow-up report of the original population previously published. [15] The results of this current follow-up show reveal continued optimum TKA performance without patient lost to followup, related complications, component failure or deterioration of the prosthetic composite. 
Continuous monitoring of total joint arthroplasty devices is of paramount importance including review of new technologies, materials and material combinations, and clinical relevance. Within the current healthcare budgetary climate and increasing healthcare costs, hospital systems are requiring increasing levels of device claims proof prior to approval and use. Currently, while the United States Food and Drug Administration (FDA) is the primary regulator of public health safety involving drugs and devices, there is no centralized technology assessment organization for technology and device monitoring. Therefore, various societies and associations have developed multiple voluntary registries that are beginning to yield published observations. [16-18] Unlike the existing international joint arthroplasty registries that are mandatory for all cases performed, voluntary participation in US domestic registries introduces a bias in the devices referenced and data collected. Prospective continuous case series studies can be used to generate information to use for publication, presentation or various hospital Value Added Technology (VAT) committees. The strategic use of large continuous patient study series may yield information that is meaningful for assessing component performance over time. Serial publications of the Total Condylar knee replacement revealed early issues with femoral component sizing, instrumentation and evolving design considerations from the original single pegged cemented patella. $[\underline{2}, \underline{10}, \underline{11}, \underline{13}]$ These items are of common knowledge today yet were not known upon the early design releases until tried and monitored. Intermediate studies have shown results for component design, patient morphology and surgical technique with and without navigation. $[\underline{6}, \underline{14}, \underline{19}-\underline{22}]$ Our results have shown favorable restoration of femoral condylar anatomy and restoration of continuous normal knee function through two and five-years in the same study population.

From our patient monitoring efforts with this study we had one patient that required revision of the tibial component following an MVA 4.5 years post-operatively. At the time of revision surgery, use of the MAXX Freedom Knee Revision tibial component was used which allowed for retention of the well-fixed and functioning index primary femoral component. The MAXX Freedom Knee Revision tibial component is engineered to be bone conserving and allows for the use of the available MAXX modular polyethylene inserts independent of femoral component constraint. This avoided the risks that are associated with prolonged surgery that would have most likely occurred with any attempt to remove the well-fixed femoral component and reimplantation of an entire revision TKA system. In addition, the multiple straight or offset stem options are available dependent on the patient's available tibial anato- my. In this specific case, a stem was required to bypass the proximal tibial fracture. There were no other patients presenting with clinical or radiographic evidence of adverse events or component failure.

As was identified in the earlier publication, this single surgeon, non-randomized consecutive case series had an imbalance of patients by gender (females $n=129$, males $n=43$ ). [15] However, other than femoral component size usage, the measured clinical outcomes were not statistically different when comparing by gender. In this population Lovenox ${ }^{\circledR}$ (Sanofi-Aventis, Bridgewater, NJ, USA) was used in all patients as their DVT prophylaxis, which has been changed to aspirin due to current results in the literature. Also, the patients included were of a Western ancestry population, so no comparative assessments to Middle-Eastern or Pan-Asian populations were available. However, efforts are being made to capture a similar study data across various ancestral populations for comparative review with the currently presented study group.

In conclusion, the reported study of patients receiving the Freedom Total Knee system for primary TKA support the design considerations for anthropomorphic considerations while achieving an increased degree of ROM while minimizing bone resection. The study included a large cohort $(n=172)$ of continuous non-selected series of patients without loss to follow-up for any reason through 5-years. In a cooperative effort between the author and the company, every effort will be made to continue study of this study population through the next follow-up landmark. From these results we believe that continued use and study is warranted to confirm achieving similar results across surgeons and to further study multiple ancestral populations.

\section{Acknowledgment}

The authors wish to thank Robert Eberle for his assistance with the preparation of this manuscript.

\section{References}

1. Rodriguez, J.A., H. Bhende, and C.S. Ranawat, Total condylar knee replacement: a 20-year followup study. Clin Orthop Relat Res, 2001(388): p. 10-7.

2. Rasquinha, V.J., et al., The press-fit condylar modular total knee system with a posterior cruciate-substituting design. A concise follow-up of a previous report. J Bone Joint Surg Am, 2006. 88(5): p. 1006-10.

3. Lonner, J.H., et al., Total knee arthroplasty in patients 40 years of age and younger with osteoarthritis. Clin Orthop Relat Res, 2000(380): p. 85-90.

4. Chon, J.G., A.V. Lombardi, Jr., and K.R. Berend, Hybrid stem fixation in revision total knee arthroplasty (TKA). Surg Technol Int, 2004. 12: p. 214-20.

5. Levitsky, K.A., et al., Total knee arthroplasty without patellar resurfacing. Clinical outcomes and long-term follow-up evaluation. Clin Orthop Relat Res, 1993(286): p. 116-21.

6. Insall, J., et al., Total condylar knee replacment: preliminary report. Clin Orthop Relat Res, 1976(120): p. 149-54.

7. Ranawat, C.S. and O. Boachie-Adjei, Survivorship analysis and results of total condylar knee arthroplasty. Eight- to 11-year follow-up period. Clin Orthop Relat Res, 1988(226): p. 6-13. 
8. Ranawat, C.S., et al., Long-term results of the total condylar knee arthroplasty. A 15-year survivorship study. Clin Orthop Relat Res, 1993(286): p. 94-102.

9. Patil, S., et al., How do knee implants perform past the second decade? Nineteento 25-year followup of the Press-fit Condylar design TKA. Clin Orthop Relat Res, 2015. 473(1): p. 135-40.

10. Walker, P.S., C. Ranawat, and J. Insall, Fixation of the tibial components of condylar replacement knee prostheses. J Biomech, 1976. 9(4): p. 269-75.

11. Ranawat, C.S., H.A. Rose, and W.J. Bryan, Replacement of the patello-femoral joint with the total condylar knee arthroplasty. Int Orthop, 1984. 8(1): p. 61-5.

12. Ranawat, C.S., H.A. Rose, and D.S. Rich, Total condylar knee arthroplasty for valgus and combined valgus-flexion deformity of the knee. Instr Course Lect, 1984. 33: p. 412-6.

13. Ranawat, C.S., The patellofemoral joint in total condylar knee arthroplasty. Pros and cons based on five- to ten-year follow-up observations. Clin Orthop Relat Res, 1986(205): p. 93-9.

14. Ranawat, C.S., W.F. Flynn, Jr., and R.G. Deshmukh, Impact of modern technique on long-term results of total condylar knee arthroplasty. Clin Orthop Relat Res, 1994(309): p. 131-5.

15. Durbhakula, S.R., L., Restoration of femoral condylar anatomy for achieving optimum functional expectations: Component design and early results. Reconstructive Review, 2016. 6(September): p. 5.

16. Ayers, D.C., et al., Using joint registry data from FORCE-TJR to improve the accuracy of risk-adjustment prediction models for thirty-day readmission after total hip replacement and total knee replacement. J Bone Joint Surg Am, 2015. 97(8): p. 668-71.

17. Etkin, C.D. and B.D. Springer, The American Joint Replacement Registry-the first 5 years. Arthroplast Today, 2017.3(2): p. 67-69.

18. Heckmann, N., et al., Early Results From the American Joint Replacement Registry: A Comparison With Other National Registries. J Arthroplasty, 2019.

19. Vaidya, S.V., et al., Anthropometric measurements to design total knee prostheses for the Indian population. J Arthroplasty, 2000. 15(1): p. 79-85.

20. Uehara, K., et al., Anthropometry of the proximal tibia to design a total knee prosthesis for the Japanese population. J Arthroplasty, 2002. 17(8): p. 1028-32.

21. Rosenstein, A.D., et al., Gender differences in the distal femur dimensions and variation patterns in relation to TKA component sizing. Orthopedics, 2008. 31(7): p. 652 .

22. Matsumoto, T., et al., Differing prosthetic alignment and femoral component sizing between 2 computer-assisted CT-free navigation systems in TKA. Orthopedics, 2011.34(12): p. e860-5.
SUBMISSION HISTORY

Submitted: March 11, 2019

Reviewed: March 16, 2019

Accepted: March 16, 2019

Published: March 31, 2019

\section{AUTHOR AFFILIATIONS}

1 Sridhar Durbhakula, M.D., Vinay S. Durbhakula, Navin S. Durbhakula Washington Joint Institute at OrthoBethesda, The Camalier Building, 10215 Fernwood Road; Suite 502, Bethesda, MD 20817

(Direct inquires to Sridhar Durbhakula, sdurbhak@gmail.com)

\section{AUTHOR DISCLOSURES}

Sridhar Durbhakula declairs either family, institution I am associated with, or I have received benefits or funds either directly or indirectly regarding this article. All other authors declare that there are no disclosures regarding the publication of this paper.

\section{COPYRIGHT \& OPEN ACCESS}

(c) 2019 Durbhakula S, Durbhakula V, Durbhakula N. All rights reserved. Authors retain copyright and grant the journal right of first publication with the work. Reconstructive Review is an open access publication and follows the Creative Commons Attribution-NonCommercial CC BY-NC. This license allows anyone to download works, build upon the material, and share them with others for non-commercial purposes as long as they credit the senior author, Reconstructive Review, and the Joint Implant Surgery \& Research Foundation (JISRF). An example credit would be: "Courtesy of (senior author's name), Reconstructive Review, JISRF, Chagrin Falls, Ohio". 